\title{
A ENFERMAGEM NO ONTEM, NO HOJE E NO AMANHĀ
}

\author{
Josicélia Dumêt Fernandes ${ }^{1}$
}

FERNANDES, J.D. A enfermagem no ontem, no hoje e no amanhã. Rev. Bras. Enf., Brasilia, 38(1): 43-48, jan./mar. 1985.

\begin{abstract}
RESUMO. $U$ presente artigo aborda os fatores determinantes da evolução da enfermagem no Brasil, visualizando algumas das contradições acerca da inserção dos enfermeiros nos programas de saúde. A partir daí, enfatiza a importância de uma atitude reflexiva como premissa básica para que se possam dimensionar as diretrizes de uma prática mais conseqüente e realista para o amanhã.
\end{abstract}

ABSTRACT. The present paper related the determining factors of nursing evolution in Brazil, showing some of contradictions about of nurses inclusion in the health programs. To start from, the importance of a reflexive attitude how basic sumption to establish the line of direction of a practice more consequent and realistic to the future is emphasized.

\section{A ENFERMAGEM NO ONTEM, NO HOJE E NO AMANHÃ}

A ação dos profissionais de enfermagem nos programas de saúde parece ser um tema simples, mas, na realidade, consiste num problema complexo, dando margem a várias interpretações. $\mathrm{E}$ este foi o motivo que nos levou à realização do presente estudo.

Considerando a complexidade do tema, teceremos comentários sobre a participação dos enfermeiros nos programas de saúde voltando ao ontem, a fim de alcançar subsídios para a compreensão do hoje e atuação no amanhã. Neste sentido, abordaremos, inicialmente, da maneira mais sucinta possível, a trajetória da prática de enfermagem nos seus determinan tes políticos, econômicos e ideológicos, como expressão concreta das políticas de saúde do nosso país ${ }^{11}, 12,13$.

Identificados os fatores determinantes da evolução histórica da enfermagem, passaremos a visualizar algumas das contradiçð̄es acerca da inserção dos enfermeiros nos atuais programas de saúde.

A partir daí, passamos a enfocar a importância de uma atitude reflexiva como premissa básica para que se possam dimensionar as diretrizes de uma prática mais conseqüente e realista para o amanhã.

\section{O ONTEM}

Até o início do presente século a "enfermagem", em nosso país, era realizada pelas irmãs de caridade nos hospitais da Santa Casa de Misericórdia. A assistência consistia, muito mais, num atendimento à miséria do que mesmo num tratamento à doença, situando-se numa ação puramente caritativa. As atividades ditas de enfermagem estavam dirigidas ao cuidado físico e espiritual do indivíduo, bem como à limpeza e ordem no interior dos hospitais.

Com a problemática da Saúde Pública, configurada na crise econômica da década de 20 , cria-se o Departamento Nacional de Saúde. Este, por sua

1 Prof essor Adjunto da Escola de Enfernagem da Universidade Federal da Bahia. 
vez, vem demarcar o aparecimento, em 1923, da primeira escola de enfermagem moderna em nosso país, que objetivava o preparo de profissionais para atuar na melhoria das condições sanitárias da população.

Nessa perspectiva, pode-se dizer que a emergência da enfermagem moderna, no Brasil, coincide com o momento em que surgem os primeiros traços de uma política de saúde por parte do Estado. E esta política estava dirigida, fundamentalmente, para o controle das epidemias, objetivando a criação de mínimas condições sanitárias indispensáveis às relaçōes de exportação e ao êxito da política de imigração que, nesse momento, procura atrair mão-de-obra para o mercado de trabalho capitalista ${ }^{4}$.

A partir daí as enfermeiras, formadas pela então Escola do Departamento Nacional de Saúde Pública, passam a participar nos programas de combate e controle das endemias, através do isolamento dos contatos.

Com o desenvolvimento do capitalismo, os trabalhadores, adquirindo certa importância política e econômica, passam a reivindicar, entre outros benefícios, melhores condições de assistência à saúde. E é nesse contexto que se implanta, em 1923, o Seguro Social no Brasil, com a Lei Eloi Chaves. A sua ampliação se dá somente após a Revolução de 1930, com a emergência de uma nova estrutura de poder, quando ele se expande para todos os assalariados urbanos (inicialmente abrangia apenas a parcela dos trabalhadores ferroviários $)^{6}$.

A criação e ampliação do sistema previdenciário, se por um lado representa a extensão de benefícios (incluindo assistência médica) a todos os assalariados urbanos, por outro, cria condições não só para assegurar maior produtividade ao setor industrial, como também para atender aos interesses capitalistas no setor saúde, à medida que passa a privilegiar a produção de serviços privados e a favorecer a expansão da rede hospitalar.

É nesse jogo de interesses que a enfermagem vai encontrar espaço para o seu desenvolvimento. Não é em vão que, somente em 1933, surge a segunda escola de enfermagem em nosso país (dez anos depois da criação da primeira escola).

Com o crescimento da população previdenciária, a saúde pública perde gradativamente a sua importância, cedendo lugar à atenção curativa hospitalar.

Assim, a partir da década de 40 , com a expansão da rede hospitalar, ocorre uma mudança no mercado de trabalho das enfermeiras. Estas, até o final da década de 30 , estavam fundamentalmente ligadas à área da saúde pública. Com o declínio desse setor e a crescente importância da Previdência Social, surge um mercado de trabalho dimensionado de acordo com o cenário da assistência hospitalar curativa ${ }^{1}$. Este novo mercado, por sua vez, vem requerer maior número de profissionais com o preparo específico para o exercício da enfermagem.

Em resposta a essa exigência, surge a Lei 775 de 6 de agosto de 1949 que reconhece o ensino de enfermagem como matéria de lei. Observe-se que, somente com o desenvolvimento do capitalismo, o ensino de enfermagem é consolidado como matéria de lei (vinte e seis anos após a sua institucionalização). Atendendo ao enfoque da época, isto é, o enfoque assistencial curativo, esta Lei destaca a necessidade do ensino das ciências físicas e biológicas e das disciplinas profissionalizantes sem dar ênfase ao ensino das ciências sociais ${ }^{5}$.

Estimula-se a criação de novas escolas, assim como de cursos de auxiliares de enfermagem e de programas de treinamento em serviços para os chamados práticos de enfermagem.

A prática de enfermagem no interior dos hospitais passa a ser configurada pelas atividades administrativas, supervisão da assistência e treinamento do pessoal auxiliar.

A partir de 1964, uma nova racionalidade é buscada pelo Estado que, através da unificação dos Institutos de Aposentadorias e Pensões, cria o Instituto Nacional da Previdência Social, em 1966. Essa unificação, consubstanciada no projeto de privação dos mecanismos democráticos das classes trabalhadoras, vem excluir a participação dos representantes dos trabalhadores na definição e gestão das políticas de saúde no setor previdênciário, que passa a ser realizada de modo corporativista entre os grandes empresários da assistência médica e os representantes do Estado ${ }^{9}$.

Essa centralização de poder vem propiciar mecanismos para uma nova expansão da rede hospitalar privado-lucrativa, da indústria de medicamentos e equipamentos, favorecendo uma estrutura assistencial fundamentada na tecnificação e sofisticação do cuidado.

Essa situação reflete-se também nos currículos das escolas de enfermagem, que, concentrando uma densa carga horária nas disciplinas do campo da assistência curativa, favorece a formação do enfermeiro para uma assistência sofisticada centra. da no âmbito hospitalar, atendendo plenamente às 
exigências do complexo médico-industrial. A prática de enfermagem passa, portanto, a ser ordenada também pela lógica e exigências do capital, assumindo papel de destaque no âmbito do econô$\operatorname{mico}^{2}, 13$.

Com o desmascaramento do "milagre brasileiro", a partir de 1972, cresce a insatisfação popular. E o Estado, necessitando legitimar e ampliar suas bases de sustentação, passa a buscar, no plano político, o apoio dos assalariados urbanos ao redifinir e expandir suas políticas sociais. Neste sentido, são operacionalizadas medidas legais de caráter administrativo. Cria-se o Conselho de Desenvolvimento Social, o Plano de Pronta Ação, ampliando-se, assim, a oferta de assistência à saúde. Cria-se, em 1974, o Ministério da Previdência e Assistência Social (órgão chave na expansão dos programas assistenciais oficiais) e, em junho de 1975, decreta-se a Leı 0.229 que dispŏe sobre a organização do Sistema Nacional de Saúde. Este, por sua vez, condiciona a posterior criação, em 1977, do Sistema Nacional da Previdência Social (SINPAS) que constitui a última unificação desse órgão.

Nesse contexto, implantam-se os Programas de Expansão de Cobertura que, traduzindo propósitos de interiorização, simplificação, regionalização e integração comunitária, abarcam amplos contingentes populacionais.

Apresentam-se propostas alternativas que, consubstanciadas nos movimentos ideológicos da Medicina Social, Medicina Preventiva e consolidadas pela Medicina Comunitária, colocam, a nível técnico, uma ampla intervenção sobre o conjunto da população. Essas propostas são apresentadas sob a forma de planos e programas cujas premissas básicas são:

- simplificação do cuidado;

- extensão de assistência básica às populaçð̄es rurais e periféricas dos grandes centros urbanos;

- ênfase nas atividades de caráter preventivo;

- expansão da rede ambulatorial;

- racionalização de recursos humanos e materiais;

- ênfase nas atividades de caráter multidisciplinar e multiprofissional.

No bojo dessas transformações, a enfermagem é também englobada pelas reformulações sociais que lhe imporem a necessidade de reformas visando a atualização de suas funçðes políticas, ideológicas e econômicas; redefine e reorganiza o modelo de assistência de enfermagem, propondo adoção de uma prática voltada para a realidade de saúde do país, com ênfase no processo saúde-enfermidade incluindo açðes de promoção, proteção e recuperação da saúde, procura oferecer uma assistência mais abrangente, ampliando o seu raio de ação e, conseqüentemente, consolidando o processo de "medicalização" da sociedade ${ }^{7}$; procura atuar em programas de saúde da população rural de saúde do escolar, de saúde materno-infantil, de saúde do trabalho, além de ampliar-se os espaços para participação nos ambulatórios. A enfermagem passa, portanto, a intervir nâo apenas sobre os doentes, os incapazes para o trabalho, os improdutivos, mas também sobre os sadios, os produtivos. E, em nome de uma ação dita preventiva, participa no controle e manutenção da força de trab lho.

Dentre as medidas apresentadas pelo setor educacional, destacam-se, dentre outras, a reformulação do processo de formação de profissionais no sentido de procurar formar um enfermeiro generalista, evitando-se a excessiva sofisticação e individualização; a utilização de métodos de ensino que incentivem a atuação multidisciplinar e multiprofissional; a integração entre o sistema de saúde e o sistema de ensino; o aperfeiçoamento de métodos e técnicas de ensino dos docentes e dos profissionais de saúde cuja unidade de prestação de serviços passe a integrar o sistema formador, além do estímulo ao desenvolvimento de cursos de pós-graduação para o preparo de docentes e para o desenvolvimento da pesquisa ${ }^{5}$.

Diante do exposto, observa-se que a prática de enfermagem estrutura-se de acordo com o conjunto dos movimentos sociais, realizando-se, desde a sua origem, vinculada ao Estado e às forças hegemônicas nas estratégias de reconstituição do poder.

A comprensão desse evoluir histórico é que vai fornecer não só o substrato para a visualização da realidade atual, no que diz respeito à questão da participação dos profissionais de enfermagem nos programas de saúde, mas também vai favorecer a orientação para o amanhã, no que diz respeito ao modo de atuar sobre aquela realidade.

\section{O HOJE}

Importa agora verificar até que ponto os profissionais de enfermagem estão efetivamente participando nos programas de saúde em nosso país.

Diríamos que a ação integral dos profissionais de enfermagem nos programas de saúde defronta-se com uma série de obstáculos no dimensionamento de sua operacionalização e isto deve-se a um 
conjunto de fatores que refletem a estrutura na qual estamos inseridos. Vejamos:

O modelo de prestação de serviços de enfermagem voltados para as atividades de caráter coletivo é quase que inexistente, em nossa realidade atual. E isto pode ser constatado pelo fato de que cerca de $80 \%$ do pessoal de enfermagem em nosso país é absorvido a nível hospitalar ${ }^{11}$. Assim é que, apesar das propostas de reativação da Saúde Pública, a enfermagem continua com a predominância de um modelo de prestação de serviços centrado nas açðes curativas e individuais, reproduzindo $o$ privilégio à assistência hospitalar, à compra de serviços ao setor privado no âmbito previdenciário, relegando a segundo plano as medidas coletivas de Saúde Pública.

Essa incoerência repercute de forma negativa na assistência à população, uma vez que cerca de $60 \%$ das açð̄es de saúde coletiva são inerentes à enfermagem ${ }^{10}$. $\mathrm{O}$ que se tem observado, em realidade, é uma escassez de recursos humanos de todos os níveis. E, dentro dessa escassez, nota-se a predominância de uma mão-de-obra elementar não qualificada e, portanto, mais barata, além de uma carêncią de profissionais de nível superior ${ }^{10}$. Com isto, contudo, não queremos induzir ao raciocínio ingênuo que alude a escassez de pessoal de enfermagem como a responsável pela inoperância dos programas, mas que essa deficiência expressa as políticas de saúde que favorecem historicamente a predominância do modelo de prestação de serviços centrado nas açōes curativas e individuais. Ademais, observe-se que a política estatal de ampliar a cobertura dos serviços de saúde coincide com o momento (conjuntura pós-74) de uma crise econômica no país que conduz à necessidade de racionalizar os recursos disponíveis. Essa necessidade leva ao incremento da extensão da assistência à saúde (não só através da assistência hospitalar, como também ambulatorial), via credenciamento e convênio do Estado com as empresas privadas, favorecendo os interesses capitalistas do setor.

Um outro aspecto a ser abordado é que, dentre as premissas básicas dos programas de saúde, está a ênfase no trabalho em equipe multiprofissional. Todavia, não se tem observado uma integração harmoniosa entre os diferentes tipos de profissionais. A enfermagem continua subordinada às diretrizes emanadas do chefe da equipe. E esta: $r$ chefia é sempre ocupada pela categoria médica. $\mathrm{O}$ médico aparece como o detentor do saber absoluto e, conseqüentemente, do poder; só a ele é dado o poder místico da formulação dos planos de ação.
Aos demais profissionais de saúde cabe a operacionalização das tarefas. Isto vem a constituir uma grande contradição, pois se preconiza a necessidade de cobrir-se parcelas mais amplas da população, a um custo razoável, no entanto as açð̄es de saúde e sua orientação imediata estão concentradas na figura do médico minimizando, como secundária e subsidiária, a ação de outros profissionais. Este monopólio do saber determinado pela hegemonia da profissão médica nada mais é do que o reflexo da materialização das relaçðes de poder existentes na sociedade.

Outro aspecto que deve ser destacado é a marginalização, o secundarismo do papel social condicionado às profissões predominantemente femininas, como é o caso da enfermagem, refletindo a sociedade em que vivemos, onde a mulher ainda é considerada intelectualmente inferior ao homem, chegando mesmo a ser chamada de "sexo frágil". Tudo isto é fruto de concepções históricas onde o fator sexo passa a ser o elemento explicativo para a marginalização da mulher ${ }^{8}$.

Outro aspecto que deve ser destacado é a marginalização, o secundarismo do papel social condicionado às profissð̋es predominantemente fmininas, como é o caso da enfermagem, refletindo a sociedade em que vivemos, onde a mulher ainda é considerada intelectuamente inferior ao homem, chegando mesmo a ser chamada de "sexo frágil". Tudo isto é fruto de concep̧̧ðes históricas onde o fator sexo passa a ser o elemento explicativo para a marginalização da mulher ${ }^{8}$.

No que diz respeito ao aparelho formador, as escolas, de acordo com seus marcos conceituais, tentam implementar atividades que não situem o hospital como elemento central das atividades. Todavia, esses órgãos continuam preparando profissionais para atender ao mercado de trabalho, com base na assistência hospitalar caracterizada pela tecnificação e sofisticação do cuidado. Ademais, a disciplina de Saúde Pública continua excluída do tronco profissional comum e as disciplinas de ciências sociais e do comportamento ocupam espaços muito reduzidos dentro do contexto curricular.

Recomenda-se a adoção de métodos de ensino integrado e de procedimentos que estimulem o trabalho em equipe; todavia, os currículos mantêm-se compostos de disciplinas estanques.

Preconiza-se a integração docente-assistencial (IDA) como forma de preparar profissionais identificados com a realidade de saúde do país; entretanto, o hospital universitário continua sendo o 
maior campo de treinamento que, por sua vez, caracteriza-se pela assistência curativa e procedimentos sofisticados.

Incrementa-se o estímulo ao desenvolvimento de pesquisas; no entanto, observa-se, na áreả da enfermagem, uma insuficiência de pesquisas que realmente contribuam para dimensionar diretrizes ajustadas aos problemas atuais.

Diante do exposto, observa-se que são adotadas soluções técnicas mantendo-se imutável a situação de fundo. Introduz-se uma pequena reforma que não muda em essência a organização e estrutura das práticas de saúde, mas recobre-as de adjetivações que as colocam como uma ampla transformação.

A serem válidas as premissas acima mencionadas, importa agora verificar os seus determinantes estruturais.

Vivemos numa sociedade estruturada em classes e grupos sociais com interesses diversos e conflitantes, onde os interesses das classes dominantes, crivados de intencionalidades das classes dominadas, é que acionam as ações do setor saúde. Em realidade, as políticas de saúde não são necessariamente determinadas pelo Estado, mas por um conjunto de instituições da sociedade civil que constituem o complexo médico-industrial, cuja eficácia consiste no seu grande poder político e econômico articulado aos interesses das multinacionais e, particularmente, na política que exclui os profissionais e a população organizada na definição, gestão e implementação das políticas de saúde ${ }^{3}$.

Nessa perspectiva, a realidade das práticas de saúde é determinada por um complexo de forças que, dentro do confronto de objetivos e interesses específicos, reflete a conjuntura político-econômica do país.

Entender as açðes dos profissionais nos programas de saúde significa visualizar esses programas como expressão das políticas estatais de saúde: "política que privilegia a assistência hospitalar e de alta sofisticação; política que perpetua a dicotomia entre o preventivo e o curativo; política que despreza as variáveis de ordem econômica, omitindo o caráter sócio-econômico global da saúde; política que substitui a voz dos profissionais e da população pela sabedoria dos tecnocratas ligados organicamente à classe hegemônica e pelas pressões dos diversos setores empresariais; política que se baseia pelos interesses de uma minoria constituída e conformada pelos donos de empresas médicas e gestores da indústria de saúde em geral".

Sob esta ótica, parece inegável que as açðes de enfermagem respondem não apenas aos condicionamentos internos, mas, sobretudo, a determinantes estruturais que delimitam espaços e papéis a serem ocupados pelos profissionais num dado momento, numa formaçāo social concreta. Por outro lado, essa constatação não exclui, de modo algum, a necessidade de compromisso com o homem social, e não apenas com o homem biológico e psicológico.

\section{O AMANHÃ}

Discutir as tendências da prática de enfermagem nas próximas décadas requer a exata compreensão do processo anteriormente descrito e uma ação substantiva que o leve em conta. Há quem diga que é inútil fazer alguma coisa porque a estrutura é muito forte. Devo dizer também que é inútil não fazer nada.

Mesmo considerando o escasso grau de interfe. rência de que dispōem os profissionais na formulação e operacionalização das políticas de saúde, isto não justifica uma omissão ensejando um imobilismo político. Ao contrário, pensamos ser oportuno avançar (e o momento é propício) em torno de proposiçðes concretas mais abrangentes, pela melhoria das condiçðes de vida e de saúde da população brasileira no amanhã. E isto só pode ser assegu. rado com uma prática comprometida com a solução dos problemas da população, através da expressão de algo que vá além do corpo, algo que seja a expressão do social, algo que leve em conta a organização social na qual vivemos. E esse compromisso implica na constituição de um pensamento crítico às formas injustas de distribuição dos serviços de saúde, à crescente dependência tecnológica, à mercantilização e privatização da saúde, ao descompasso entre a escola, a realidade do mercado e as necessidades de saúde da população.

A condução dessas ações deve pautar-se funda. mentalmente na busca de:

- uma compreensão da prática dos profissionais de saúde em termos de relações sociais mais amplas, evitando-se o pensamento idealista de soluções isoladas do conhecimento técnico com sua enunciada e presumida neutralidade;

- uma análise objetiva dos aspectos estruturais e conjunturais da prática dos profissionais de saúde valorizando o quadro econômico, político e social no qual ela se desenvolve, evitando-se o entorpecimento dos principais fatores determinantes;

- um relacionamento da prática dos profissio- 
nais de saúde com as políticas sociais que săo a expressão da intervenção do Esstado como resposta aos confrontos de interesses entre grupos sociais conflitantes.

Nessa perspectiva, consideramos de fundamental importância os seguintes encaminhamentos preliminares:

- promover debates sobre a questão da saúde junto aos trabalhadores do setor através de suas entidades, incluindo sindicatos, associações de classe, associações de bairros e grupos religiosos;

- defender a representação permanente das associações de profissionais de saúde e da população nos órgãos decisórios relativos ao setor de saúde;

- reiterar a crítica contra a política privatizante da Previdência Social, pois esta política, além de expandir a mercantilização e facilitar a penetração das multinacionais na assistência à saúde, é a responsável pela exaustão de recursos financeiros daquele órgão.

\section{CONSIDERAÇÕES FINAIS}

Antes de concluirmos esta apresentação, gostaríamos de dizer que não estamos aqui para trazer a fórmula mágica, para dar soluçðes imperialistas. Cremos que os profissionais unidos por uma finalidade é que devem procurar soluções. Sabemos que não é fácil, mas se amanhã todos começarem a fazer um trabalho de transformação, independentemente do seu poder institucional, já seria um grande passo para a tentativa de resolução das questões aqui colocadas. Por outro lado, se muitos de nós, amanhã, retornarmos ao nosso trabalho como se nada houvesse acontecido, aí acreditamos que a situação, aqui detonada, persistirá. É muito difícil ir além de uma leitura como esta, que não fique aqui só a nível de estudo. Esperamos que os profissionais de enfermagem possam transformar suas práticas de trabalho com a esperança de encontrar uma solução. E esta esperança deve estar dentro de nós como expressão de nossas contradiçð̄es, porque o outro, o doente, é outro de nós.

FERNANDES, J.D. The pass, present and future of nursing. Rev. Bras. Enf., Brasília, 38(1): 43-48, jan./mar. 1985.

\section{REFERENNCIAS BIBLIOGRAFICAS}

1. ALCÂntara, G. A enfermagem como categoria profissional: obstáculos à sua expansão no sociedade brasileira. Ribeirão Preto, S.P., 1966. Tese (Cátedra) - USP. Esc. Ent. Ribeirão Preto.

2. ALMEIDA. M.C.P. et alii. Contribuição ao estudo da prática de enfermagem - Brasil. s.n.t. (mimeografado).

3. ASSOCIAÇÃO PSIQUIÄTRICA DA BAHIA/CENTRO BRASILEIRO DE ESTUDOS EM SAÜDE/ BAHIA. Política de saúde mental do Brasil. Rev. Assoc. Psiq. Ba., Salvador, 4:7-15, 1981.

4. BRAGA, J.C.S. A questão da saúde no Brasil: um estudo das políticas sociais em saúde pública $e$ medicina previdenciária no desenvolvimento capitalista. Rio de Janciro, 1978. Tese (Mestrado) UNICAMP.

5. BRASIL. Ministério da Educação e Cultural. Departamento de Assuntos Universitários. Estudos sobre a formação e utilização dos recursos humanos na área cla saúde. Brasília, Departamento de Documentação e Divulgação, 1976.

6. DON'ANGELO, M.C.F. Medicina e sociedade; o médico e seu mercado de trabalho. São Paulo, Pioneira, 1975. (Biblioteca pioneira em ciências sociais. Sociologia).

7. Saúde e sociedade. São Paulo, Duas Cidades, 1976.

8. IELRNANDLS, J.D. Contribuição da equipe multiprofissional nas ações de saúde - mito ou realidade? Rev. Bras. Enf., Brasília, 34 (2):175-81, abr./ jun. 1981.

9. LUZ, M.T. As instituiçōes médicas no Brasil; instituição e estratégia de hegemonia. 2. ed. Rio de Janeiro, Graal, 1979. (Biblioteca de saúde e sociedade, v. 6).

10. MATOS, A.V. A enfermagem e o Sistema Nacional de Saúde. In: CONGRESSO BRASILEIRO DE ENFERMAGEM, 30., Belém, 16 a 22 de julho de 1978. Anais... Brasília, ABEn, 1978. p. 13-30.

11. OLIVEIRA, M.I.R. Enfermagem e estrutura social. In: CONGRESSO BRASILEIRO LE ENFERMAGEM, 31., liortaleza, 5 a 11 de agosto de 1979. Anois... Fortaleza ABEn, 1979. p. 9-26.

12. SILVA, A.L.C. et alii. Marco conceitual e estrutural dos currículos dos cursos de graduação em enfermagem. In: CONGRESSO BRASILEIRO DE ENFERMAGEM, 31., Fortaleza, ABEn, 1979. p. 107-14.

13. VERDERESE, O. Análisis de la enfermería en la América Latina. Educ. Méd. Salud, 13 (4):315$40,1979$. 